\title{
Estimation of glomerular filtration rate from plasma creatinine concentration in children
}

\author{
R. COUNAHAN, C. CHANTLER, S. GHAZALI, BETTY KIRKWOOD, \\ FRANCES ROSE, and T. M. BARRATT \\ From the Department of Immunology, Institute of Child Health, and Department of Paediatrics, Guy's Hospital, \\ London; and Central Public Health Laboratory, Colindale
}

Counahan, R., Chantler, C., Ghazali, S., Kirkwood, B., Rose, F., and Barratt, T. M. (1976). Archives of Disease in Childhood, 51, 875. Estimation of glomerular filtration rate from plasma creatinine concentration in children. The relation between the true plasma creatinine concentration $\left(P_{c}\right)$ and the glomerular filtration rate corrected for body surface area (GFR/SA) was investigated in 108 individuals, and the following formula was derived: GFR/SA $\left(\mathrm{ml} / \mathrm{min}\right.$ per $\left.1.73 \mathrm{~m}^{2} \mathrm{SA}\right)$ $=0.43 \mathrm{Ht}(\mathrm{cm}) / \mathrm{P}_{\mathrm{c}}(\mathrm{mg} / 100 \mathrm{ml})$. This formula was tested in a second group of 83 children, and its accuracy and precision was compared to the 24-hour creatinine clearance. It was found to be superior to the creatinine clearance overall, and was as good, even if all results involving suspect 24-hour-urine collections were eliminated from analysis. The formula in SI usage is: GFR/SA (ml/min per $\left.1.73 \mathrm{~m}^{2} \mathrm{SA}\right)=38$ $\mathrm{Ht}(\mathrm{cm}) / \mathbf{P}_{\mathrm{c}}(\mu \mathrm{mol} / \mathrm{l})$.

The estimation of glomerular filtration rate (GFR) is of central importance in assessment of renal function. However, the most precise methods are too cumbersome for routine clinical use, and in practice a compromise between accuracy and simplicity has to be sought. The 24-hour creatinine clearance $\left(C_{c}\right)$ is widely used to estimate GFR, but difficulties in the accurate collection of timed urine samples, particularly from children, limit its value, and even under research conditions its reproducibility is poor (Chantler and Barratt, 1972). Because creatinine excretion is approximately constant, an inverse relation exists between GFR and the plasma creatinine concentration $\left(P_{c}\right)$, and formulae for the estimation of GFR from $P_{c}$ in adults have been presented (Doolan, Alpen, and Theil, 1962; Jelliffe, 1971; Cockcroft and Gault, 1976). In healthy children, however, $P_{c}$ rises with age (Donckerwolcke et al., 1970), whereas GFR, corrected in accordance with convention for body surface area (SA) does not do so after the age of 2 years. It is therefore apparent that the relation between $P_{c}$ and GFR/SA in children must reflect some further aspect of body size. Taking into account the fact that creatinine excretion $\left(U_{c} V\right.$; $\mathrm{U}_{\mathrm{c}}=$ urine creatinine concentration, $\mathrm{V}=$ urine

Received 20 February 1976. flow rate) is proportional to body weight (Wt) (Graystone, 1968), we argued that GFR/SA should be proportional to body height $(\mathrm{Ht})$ and inversely proportional to $\mathrm{P}_{\mathrm{c}}$ :

(i) $\mathrm{GFR} \propto \mathrm{C}_{\mathrm{c}}=\mathrm{U}_{\mathrm{c}} \mathrm{V} / \mathrm{P}_{\mathrm{c}}$

(ii) $\mathrm{U}_{\mathrm{c}} \mathrm{V} \propto \mathrm{Wt}$

(iii) Wt $\propto$ cube of height $\left(\mathrm{Ht}^{3}\right)$

(iv) $\mathrm{SA} \propto$ square of height $\left(\mathrm{Ht}^{2}\right)$, substituting the proportionalities (ii), (iii), and (iv) in (i):

(v) $\mathrm{GFR} / \mathrm{SA} \propto \mathrm{Ht} / \mathrm{P}_{\mathrm{c}}=\mathrm{a} \mathrm{Ht} / \mathbf{P}_{\mathrm{c}}$. The same conclusion was reached empirically by Schwartz et al. (1976).

We analysed the data from a first group of 108 individuals to estimate the proportionality constant $a$, and then compared the accuracy of the estimation of GFR from equation (v) with the 24-hour $\mathrm{C}_{c}$ in a second group of 83 individuals; we found that the estimate of GFR/SA from $P_{c}$ was as good as that obtained from $\mathrm{C}_{\mathrm{c}}$.

\section{Patients}

Group I consisted of 103 children with renal disease and 5 healthy adults; the children were between 2 months and 14 years of age, and had various renal diseases but were not oedematous. They were in a 
stable state with GFR in the range $4-200 \mathrm{ml} / \mathrm{min}$ per $1 \cdot 73 \mathrm{~m}^{2} \mathrm{SA}$. For group II, 83 children with kidney disease consecutively admitted to the renal ward, who had both $C_{c}$ and GFR determined within an 8-day period, were identified. In both groups only the first relevant result in each child was recorded for analysis.

\section{Methods}

GFR was estimated from the plasma clearance of 51chromium edetic acid ( $\left.{ }^{51} \mathrm{Cr}-\mathrm{EDTA}\right)$ after intravenous injection. Blood samples were collected at 2 and 4 hours and GFR calculated by a single exponential analysis incorporating the correction factor described by Chantler and Barratt (1972). Surface area was derived from height and weight using the formula of $\mathrm{Du}$ Bois and $\mathrm{Du}$ Bois (1916) and GFR was corrected to 1.73 $\mathrm{m}^{2} \mathrm{SA}$.

In group $I, P_{c}$ was determined manually in duplicate by the Jaffé reaction after adsorption onto an ion-exchange resin to remove noncreatinine chromogens (Stoten, 1968), and also by an automated method (Technicon, 1966). The latter method includes some noncreatinine chromogens, and was found to overestimate the true creatinine concentration by 0.14 $\mathrm{mg} / 100 \mathrm{ml} \pm 0 \cdot 13$ (SD). In group II only the automated method was used, and the true value for $P_{c}$ estimated by subtracting $0.14 \mathrm{mg} / 100 \mathrm{ml}$. Throughout this paper, $P_{c}$ refers to the true plasma creatinine concentration.

Creatinine clearance was calculated from a single 24-hour urine collection and a single determination of the plasma creatinine concentration by the automated method without the correction for noncreatinine chromogens. Urine creatinine concentration was measured by the same automated method as for plasma with different dilution factors. Urine collections were judged to be accurate if the creatinine excretion fell within the following limits (Ghazali and Barratt, 1974): $U_{c} \mathrm{~V} / \mathrm{Wt}(\mathrm{mg} / \mathrm{kg}$ body weight per day) $=15+0.5 \times$ Age (years) \pm 6 (2SD). $26(31 \%)$ of the 8324 -hour urine collections failed to satisfy this criterion.

\section{Results}

Relation of $P_{c}, H$, and GFR/SA (group I). The relation between $P_{c}$ and GFR/SA in the first group of individuals is shown in Fig. 1. The data have been treated logarithmically to stabilize variances. The symbols indicate groups of patients of different height, and the effect of height on the relation between $P_{c}$ and GFR/SA is apparent.

Theoretical considerations given above suggested the following relation: $\mathrm{GFR} / \mathrm{SA}=\mathrm{a} \mathrm{Ht} / \mathrm{P}_{\mathrm{c}}$, which was also indicated by the plot of $\log$ GFR/SA against $\log \mathrm{Ht} / \mathrm{P}_{\mathrm{c}}$ (Fig. 2). The more general form was first considered, GFR/SA $=a \mathrm{Ht}^{\mathrm{b}} \mathrm{P}_{\mathrm{c}}{ }^{\mathrm{c}}$, which is equivalent to $\log \mathrm{GFR} / \mathrm{SA}=\log \mathrm{a}+\mathrm{b} \log \mathrm{Ht}+\mathrm{c} \log$ $\mathbf{P}_{\mathrm{c}}$

A multiple linear regression was undertaken. The test of regression ( $b=c=o$ ) was highly

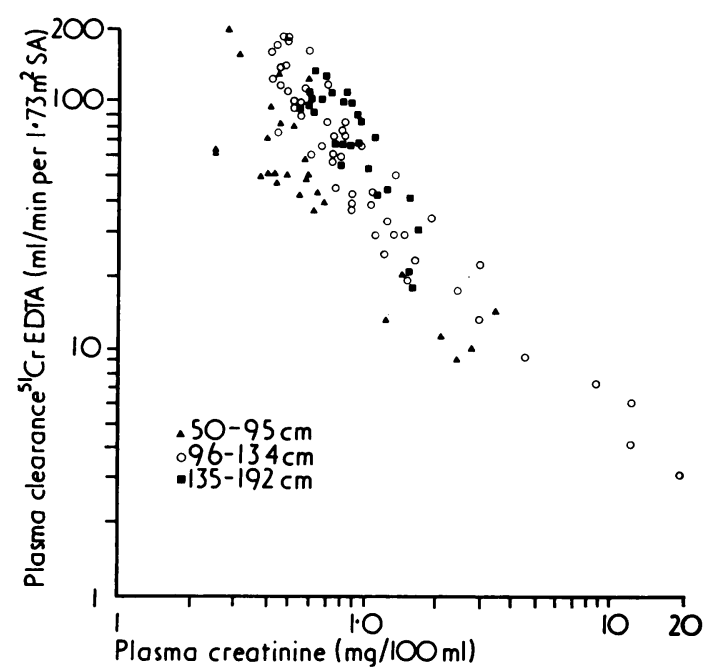

FIG. 1.-Comparison of the true plasma creatinine concentration and glomerular filtration rate/body surface area $(G F R / S A)$ in 103 children and 5 adults (group $I$ ).

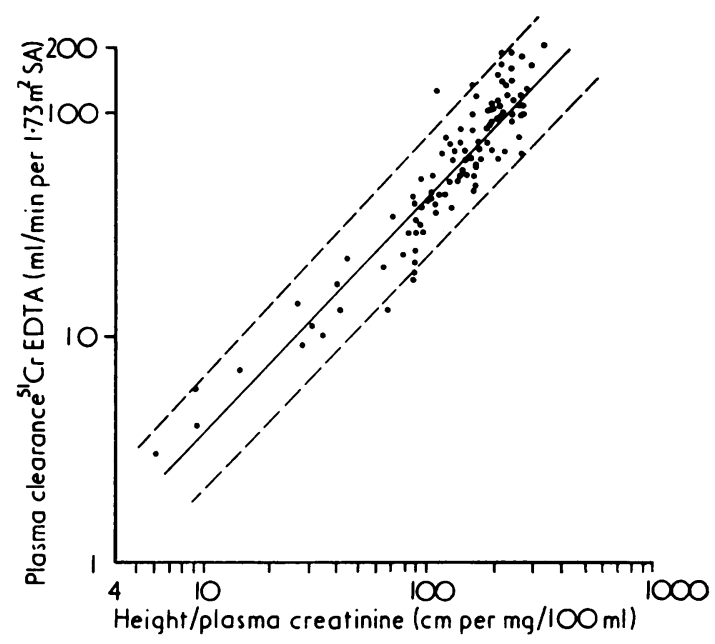

FIG. 2.-Relation between GFR/SA and body height divided by the true plasma creatinine concentration (group I).

significant, as was the test for including $b$ in the model given that $c$ was included. However, the estimates of $b$ and $-c$ did not differ significantly from unity. It was therefore assumed that $b=-c$ $=1$, i.e. $\log \mathrm{GFR} / \mathrm{SA}=\log \mathrm{a}+\log \mathrm{Ht}-\log \mathrm{P}_{\mathrm{c}}$. The least-squares estimate of $\log a$ was $\log a=$ -0.37 , estimated standard error $=0.01$.

The estimated standard error of the predicted value of $\log$ GFR/SA from the observed value of 
$\log \mathrm{Ht}$ and $\log \mathrm{P}_{\mathrm{c}}$ is $0 \cdot 14$. This model accounted for $87 \%$ of the variation in log GFR/SA. Its validity was tested by calculating and examining the residuals, and there was good evidence that they were normally distributed. From this analysis the best estimate of $a$ is 0.43 . Therefore, to predict GFR/SA from $\mathrm{Ht}$ and $\mathrm{P}_{\mathrm{c}}$ the relation is GFR/SA $=0.43 \mathrm{Ht} / \mathrm{P}_{\mathrm{c}}$.

The $95 \%$ confidence limits for the predicted value of GFR/SA are $0.43 \mathrm{Ht} / \mathrm{P}_{\mathrm{c}}{ }^{10 \pm 0 \cdot 28}$, i.e. 52 and $190 \%$ of the estimated value.

Prediction of GFR/SA from $C_{c}$ and $P_{c}$ (group II).

$C_{c}$ and $G F R / S A$. The relation between the 24hour $\mathrm{C}_{\mathrm{c}} / \mathrm{SA}$ and the measured GFR/SA in all the 83 children in group II is shown in Fig. 3. The

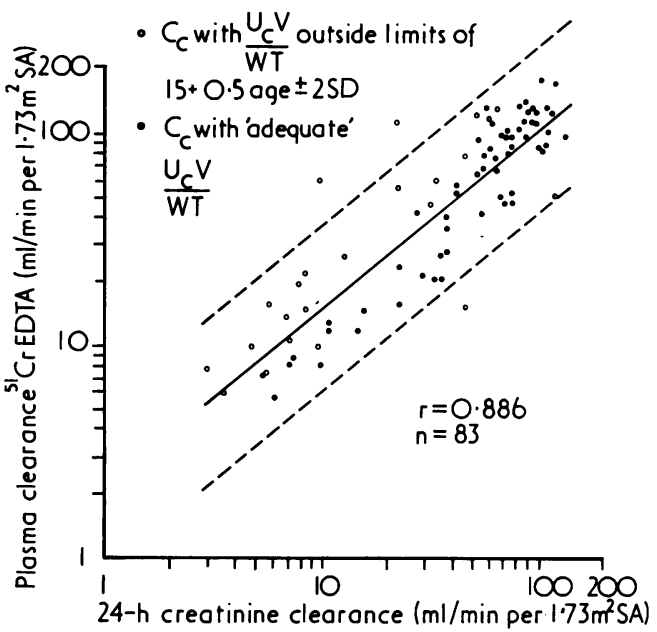

FIG. 3.-Relation between the 24-hour $C_{\mathrm{c}} / S A$ and GFR/ $S A$ (group II).

correlation is highly significant, but the scatter of the observations is wide $(\mathrm{r}=0.89, \mathrm{P}=<0.001)$. When the 26 children with inadequate urine collections were excluded from the analysis, the relation of $\mathrm{C}_{\mathrm{c}} / \mathrm{SA}$ and GFR/SA was better $(\mathrm{r}=0.94, \mathrm{P}=$ $<0.001)$, and the scatter of observations narrower (Fig. 4).

$0.43 \mathrm{Ht} / P_{c}$ and $G F R / S A$. GFR/SA predicted by the formula derived from the analysis of group I correlated well with the measured GFR/SA $(r=0.95, n=83, P=<0.001)$ (Fig. 5).

Comparison of $0.43 \mathrm{Ht} / \mathrm{P}_{c}$ and $\mathrm{C}_{c} / S A$ as estimate of $G F R / S A$. In order to compare the two methods of estimating GFR, the mean and

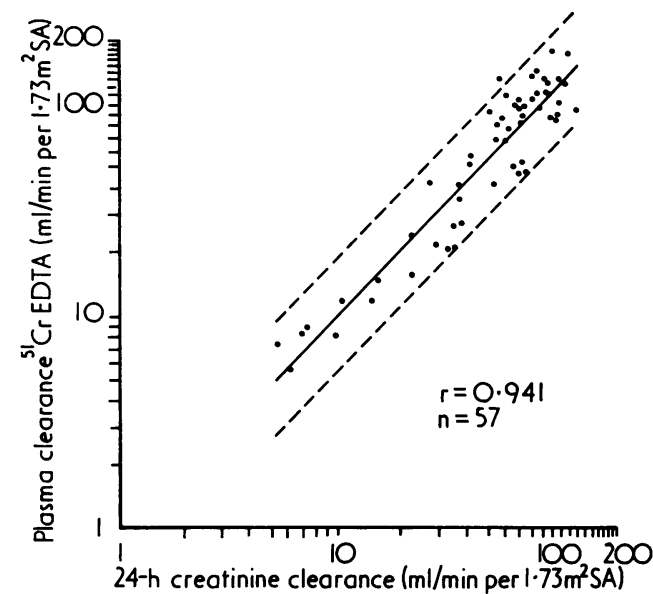

Fig. 4.-Relation between the 24-hour $C_{\mathrm{c}} \mid S A$ and $G F R /$ $S A$ after exclusion of children with inadequate urine collections (group II).

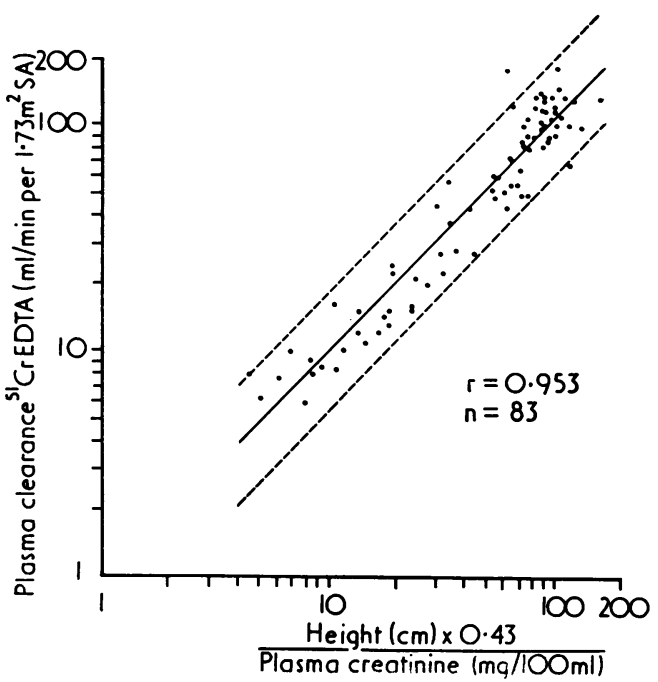

Fig. 5.-Relation between $G F R / S A$ estimated from the height and plasma creatinine concentration and that measured by the plasma clearance of ${ }^{51} \mathrm{Cr}-E D T A$ (group II).

variances of their individual differences from the measured GFR were analysed. The data were again treated logarithmically, and for each individual a value for $d A$ and $d B$ calculated, where $\mathrm{dA}=\log \mathrm{GFR} / \mathrm{SA}-\log \left(0.43 \mathrm{Ht} / \mathrm{P}_{\mathrm{c}}\right), \mathrm{dB}=\log$ GFR/SA- $\log \mathrm{C}_{\mathrm{c}} / \mathrm{SA}$.

The mean value for $d A$ was not significantly different from zero (Table) whereas $\mathrm{dB}$ for the whole group of 83 children was significantly positive, 
TABLE

Means, standard errors, and $P$ values for differences from zero of $d A$ and $d B$

\begin{tabular}{|c|c|c|c|c|}
\hline Method & $\mathbf{n}$ & $\bar{d}(A$ or $B)$ & $S E(\bar{d})$ & $\mathbf{P}$ \\
\hline $\begin{array}{c}0.43 \mathrm{Ht} / \mathrm{P}_{\mathrm{c}} \\
\mathrm{C}_{\mathrm{c}} / \mathrm{SA} \\
{ }^{*} \mathrm{C}_{\mathrm{c}} / \mathrm{SA}\end{array}$ & $\begin{array}{l}83 \\
83 \\
57\end{array}$ & $\begin{array}{r}-0.005 \\
0.099 \\
0.033\end{array}$ & $\begin{array}{l}0 \cdot 014 \\
0 \cdot 023 \\
0 \cdot 018\end{array}$ & $\begin{array}{l}>0.5 \\
<0.001 \\
<0.1\end{array}$ \\
\hline
\end{tabular}

$\mathrm{dA}=\log \mathrm{GFR} / \mathrm{SA}-\log \left(0.43 \mathrm{Ht} / \mathrm{Pc}_{\mathrm{c}}\right)$.

$\mathrm{dB}=\log \mathrm{GFR} / \mathrm{SA}-\log \mathrm{C}_{\mathrm{c}} / \mathrm{SA}$.

*Adequate 24-hour urine collections only.

indicating an underestimate by $\mathrm{C}_{\mathrm{c}} / \mathrm{SA}$. However, when the 26 estimates with inadequate urine collection were excluded, $\mathrm{dB}$ was not significantly different from zero.

The variances of $\mathrm{dA}$ and $\mathrm{dB}$ were compared as for a paired sample (see for example Armitage, 1971). When the 26 individuals were excluded as above, there was no significant difference between them $(P>0 \cdot 2)$, but when all 83 individuals were considered the variance of $\mathrm{dB}$ was significantly greater than that of $d A(P<0.001)$. This analysis implies that $0.43 \mathrm{Ht} / \mathrm{P}_{\mathrm{c}}$ as an estimate of GFR/SA is superior to $C_{c} / S A$ overall, and is just as good even when criteria are applied to exclude estimates of $\mathrm{C}_{\mathrm{c}} / \mathrm{SA}$ based on 24-hour urine collections of dubious adequacy.

\section{Discussion}

This study shows that measurement of $P_{c}$ provides a simple and reliable method of estimating GFR in children, provided that height is taken into consideration. The formula GFR/SA $(\mathrm{ml} / \mathrm{min}$ per $\left.1.73 \mathrm{~m}^{2} \mathrm{SA}\right)=0.43 \mathrm{Ht}(\mathrm{cm}) / \mathrm{P}_{\mathrm{c}}(\mathrm{mg} / 100 \mathrm{ml})$, is based on the true plasma creatinine concentration; using the commonly available automated method, $0.14 \mathrm{mg} / 100 \mathrm{ml}$ should be subtracted to allow for noncreatinine chromogens. If SI units are used, and plasma creatinine concentration expressed in $\mu \mathrm{mol} / \mathrm{l}$, the formula should be rewritten: GFR/SA $\left(\mathrm{ml} / \mathrm{min}\right.$ per $\left.1.73 \mathrm{~m}^{2} \mathrm{SA}\right)=38 \mathrm{Ht}(\mathrm{cm}) / \mathbf{P}_{\mathrm{c}}(\mu \mathrm{mol} / \mathrm{l})$ and $12.4 \mu \mathrm{mol} / 1$ should be subtracted from the automated estimates of $\mathbf{P}_{\mathrm{c}}$.

Our statistical analysis has shown that this method of estimating GFR is as accurate and as precise as measuring the 24-hour $\mathrm{C}_{\mathrm{c}}$, even when urine is collected on a ward specializing in the care of children with renal disease, and when results are eliminated if the creatinine excretion does not fall within the normal range, implying erroneous urine collections.

Our conclusion, therefore, is that the 24-hour $\mathrm{C}_{c}$ should be abandoned as an estimate of GFR in children except in special circumstances such as emaciation were creatinine production may be low, in changing states where the actual $P_{c}$ does not represent the equilibrium value, and in special tests where $C_{c}$ can be used as an internal reference clearance. It is possible, however, that greater precision may be obtained with shorter urine collections for measurement of $\mathrm{C}_{c}$, but we have not examined this point.

Schwartz et al. (1976) have undertaken a similar analysis to our own, and present the formula: GFR/SA (ml/min per $\left.1.73 \mathrm{~m}^{2} \mathrm{SA}\right)=0.55$ length $(\mathrm{cm}) / \mathrm{P}_{\mathrm{c}}(\mathrm{mg} / 100 \mathrm{ml})$. The difference between their value of 0.55 and ours of 0.43 can be explained by the fact that they did not measure true plasma creatinine concentration, and used the inulin clearance as reference estimate of GFR.

It should be recognized, however, that the error of estimation of GFR/SA from $P_{c}$ is large, the $95 \%$ confidence limits being $52-190 \%$. Nevertheless, measurement of 24-hour $\mathrm{C}_{c}$ does not reduce this error, and if more precise estimates of GFR are necessary, other methods, such as the plasma clearance of ${ }^{51} \mathrm{Cr}$-EDTA should be used.

We thank Professor B. E. Clayton for the automated plasma creatinine and urine creatinine determinations.

\section{REPERENCES}

Armitage, P. (1971). Statistical Methods in Medical Research, p. 165. Blackwell Scientific Publications, Oxford.

Chantler, C., and Barratt, T. M. (1972). Estimation of glomerular filtration rate from plasma clearance of 51-chromium edetic acid. Archives of Disease in Childhood, 47, 613.

Cockcroft, D., and Gault, M. H. (1976). Predicting creatinine clearance from serum creatinine. Nephron, 16, 31.

Donckerwolcke, R. A. M. G., Sander, P. C., Van Stekelenberg, G. J., Stoop, J. W., and Tiddens, H. A. W. M. (1970). Serum creatinine values in healthy children. Acta Paediatrica Scandinavica, 59, 399.

Doolan, P. D., Alpen, E. L., and Theil, G. B. (1962). A clinical appraisal of the plasma concentration and endogenous clearance of creatinine. American fournal of Medicine, 32, 65.

Du Bois, D., and Du Bois, E. F. (1916). Clinical calorimetry. X. Formula to estimate the approximate surface area if height and weight be known. Archives of Internal Medicine, 17, 863.

Ghazali, S., and Barratt, T. M. (1974). Urinary excretion of calcium and magnesium in children. Archives of Disease in Childhood, 49, 97.

Graystone, J. (1968). Creatinine excretion during growth. Human Growth, p. 182. Ed. by D. B. Cheek. Lea and Febiger, Philadelphia.

Jelliffe, R. W. (1971). Estimation of creatinine clearance when urine cannot be collected. Lancet, 1, 975.

Schwartz, G. J., Haycock, G. B., Edelmann, C. M., and Spitzer, A. (1976). A simple estimate of glomerular filtration rate in children derived from body length and plasma creatinine. Journal of Pediatrics, 58, 259.

Stoten, A. J. (1968). A micromethod for creatinine using resin to remove interfering substances. Fournal of Medical Laboratory Technology, 25, 240.

Technicon Instrument Company (1966). Autoanalyst, 1, 89.

Correspondence to Dr. T. M. Barratt, Department of Immunology, Institute of Child Health, 30 Guilford Street, London WC1N IEH. 